\title{
MALPOSITION OF THE KIDNEYS;
}

ABSENCE OF THE VAGINA, UTERUS, AND FALLOPIAN TUBES ;

DISEASE OF LEFT OVARY.

BY R. BOYD, M.D.,

REMIDENT PHYSICIAN TO ST. MARYLEBONE INFIRMARY, AND LECTURER ON MEDICINE.

Communicated by JOHN G. PERRY, Esq.

READ MAY 11TH, 1841.

Sarah Richardson, æt. seventy-two, died under my care in the St. Marylebone workhouse, of chronic disease of the brain and lungs. The body was examined on the 6th March last, twenty-four hours after death. From the following peculiarities which presented themselves in the genito-urinary organs, it occurred to me to submit the case, with the preparation of the parts, to the notice of the Fellows of this Society.

The renal capsules were in their usual position, on either side the spine, immediately below the diaphragm. Right kidney situated in the right iliac fossa, below the cæcum, partially concealed by the right ovary, which had a slight peritoneal attachment to it. The renal artery was given off from the right iliac, close to the aorta. 
Left kidney in the pelvis below the psoas muscle, resting on the sacrum and origin of the pyriform muscle. An artery which arose from the aorta at its bifurcation, in the situation of the middle sacral, entered the upper end of the kidney; another larger branch from the internal iliac artery, entered the kidney in the usual situation.

Kidneys, ureters, and bladder, in a healthy condition. Right ovary, when divided, presented the natural structure; to its upper or free extremity was attached, by a thin neck, a small oval sac. A round ligament connected the ovary to, and was lost in, the cellular tissue behind the neck of the bladder.

The situation of the left ovary was occupied by a fibrous tumour of an irregular globular shape, connected by a round ligament smaller than that on the right side, but which took a similar course to the bladder.

The Fallopian tubes were not present. There was a slight projection of the peritoneum, behind the bladder, from cellular tissue beneath it. A careful examination of the parts in their recent state was made by Dr. R. Lee, also by Mr. Kiernan, afterwards by Mr. Perry, - no vestige of uterus could be discovered.

The external parts of generation presented no unusual appearance; the mons Veneris but thinly covered with hair: a cul de sac, about half an inch deep, beneath the orifice of the urethra, is all that exists of vagina. 
Mammæ were well developed for so old a person. The disconnection, in this instance, between the renal capsules and the kidneys, seems to favour $\mathrm{Mr}$. Gulliver's views as to the functions of the former organs. From Mr. Gulliver's observations it would appear, that the renal capsules secrete a peculiar matter, which may be found in the veins, from which it follows, that these organs are glands, to which the veins serve as ducts. The renal capsules therefore are probably quite unconnected in function with the secretory glands, as the kidneys.

As regards the previous history of this woman, the only information obtained was, that she had been married, but did not live on amicable terms with her husband.

It will be remembered, that in the memorable case of the unfortunate Hannah Brown, murdered by Greenacre, the absence of the uterus was, as in this case, observed: it may therefore be useful to record, from time to time, such other instances of this curious malformation as may present themselves to practitioners. 